\title{
DE LA ÉTICA A LA LEY, EL INEVITABLE O EVITABLE PESO DE LA REACCIÓN SOCIAL FORMAL EN EL ÁMBITO CIVIL. EL CASO DE LA LEGISLACIÓN EN EL DISTRITO FEDERAL
}

FROM ETHICS TO LAW, THE INEVITABLE OR AVOIDABLE BURDEN OF FORMAL SOCIAL REACTION IN THE CIVIL SPHERE. THE CASE OF LEgISLATION

in THE Federal District

DE L'ÉTHIQUE AU DROIT, LE FARDEAU INÉVITABLE OU ÉVITABLE DE LA RÉACTION SOCIALE FORMELLE DANS LE DOMAINE CIVIL. LE CAS

DE LA LÉGISLATION DANS LE DisTRICT FÉdÉRAL

María Leoba Castañeda Rivas*

\section{Planteamiento}

El derecho constituye la última medida de la sociedad para salvaguardar valores fundamentales y orientar el comportamiento de los miembros de una sociedad o de una comunidad.

Se tiene la idea, derivada de algunas teorías jurídicas, que el derecho es un reflejo de la sociedad, esto es, que el contenido de las normas jurídicas deben reflejar las relaciones que se dan en la sociedad. Sin embargo, sin dejar de lado esa posibilidad, existe también la opción de que las normas planteen una relación dialéctica con la realidad social, de tal manera que la sociedad implica una serie de estímulos sobre la norma y ésta a la vez, a través de la actuación del legislador, regresa una respuesta en su pretensión de orientar la conducta del ser humano que vive en esa sociedad y luego, la propia sociedad da una nueva respuesta a esa pretensión y de nuevo la norma, esto es, el legislador a través de su actividad como creador de la norma y con el apoyo de los jueces, que "miden el pulso" del propio contenido normativo, tratar de dar nuevas respuestas que de nuevo, tratan de incidir sobre la realidad social.

Bajo el imperativo de esta relación dialéctica, las normas se van ajustando, se van perfeccionando o por lo menos se hacen cada vez más complejas.

El retorno continuo a una institución jurídica denota tal vez, cierta reticencia social a acatarla, este es el caso de la norma relacionada con la obligación de cumplir la obligación alimentaria en nuestro sistema jurídico.

* Licenciada en Derecho por la Universidad Nacional Autónoma de México. Doctora en Derecho por la misma casa de estudios. 
El proceso de cambio, de ajuste, de vinculación con el aspecto penal y en su caso, la creación de instituciones administrativas adicionales para poder reforzar el cumplimiento en la materia antes mencionada, dan cuenta de una reticencia muy grande por parte de una porción, al parecer muy grande, de la población, por cumplir con las obligaciones correspondientes, ello al parecer se vuelve más significativo en el caso de los divorcios y cuando la obligación recae en los varones, que por principio, dado el rol que socialmente se ha asignado, es el responsable, dentro de la relación matrimonial, de ser el proveedor en la familia.

Frente a esa realidad, el legislador ha respondido con un conjunto de reformas que tienen como propósito obligar a lo que se ha denominado como "deudores alimentarios morosos". Sin embargo, parece que esas medidas o tendrán que hacerse mucho más rígidas, más punitivas y más persecutorias para obligar a los deudores alimentarios morosos a cumplir, o tendrá que atacarse por otro camino el problema, dado que es probable que el enfoque juridicista no se sea totalmente el adecuado para combatir el fenómeno social que se considera por supuesto poco favorable para una parte muy importante de la población y que además es muy vulnerable: los niños cuyos padres se divorcian y que quedan bajo la guarda y custodia de las madres y cuyos padres no solventan su responsabilidad de otorgar alimentos.

El propósito de este artículo es analizar muy brevemente la evolución y la pertinencia de las reformas más recientes en materia de la obligación de otorgar alimentos, el efecto que ha tenido sobre el fenómeno social de los deudores alimentarios morosos y la responsabilidad civil que se les imputa y analizar, un poco, sobre los condicionamientos culturales que tiene el propio incumplimiento, sin dejar de lado los factores de carácter económico.

Se plantea por supuesto, que la ley constituye un tipo de reacción social formal, que en teoría es el más eficaz, por la fuerza que le confiere la posibilidad coactiva, pero que en ocasiones, no es suficiente para poder "reorientar" debidamente una tendencia de comportamiento cuyos elementos son complejos, históricamente hablando.

\section{TEORÍA JURÍDICA Y “SENTIDO COMÚN"}

El derecho da por sentado muchas situaciones, en lo que parece una extensión del sentido común que se concreta en el contenido de las normas, muy frecuentemente en las leyes; puede no serlo o no corresponder con la realidad.

Se da por sentado, por ejemplo, que la norma es un reflejo de la sociedad, esto quiere decir que la norma refleja el tipo de relaciones interpersonales que se dan en la sociedad. También, que puede reflejar el ideal de las relaciones que se dan en la sociedad. La idea no siempre es precisa, muchas personas ajenas a la teoría jurídica, suponen que ese tipo de relaciones se reduce al presente, en algunas de las teorías del derecho, se pretende que esas relaciones sean para siempre.

Situamos a partir de estas ideas, cuatro presupuestos: 
a) La norma regula las relaciones interpersonales y ello opera para el presente;

b) La norma regula las relaciones interpersonales y ello opera para siempre;

c) La norma plantea el ideal de las relaciones interpersonales y ello opera el presente,

d) La norma plantea el ideal de las relaciones interpersonales y ello opera para para siempre.

Las diferencias son significativas, el considerar o dar por sentado que la norma regula en el presente, deja abierta la posibilidad de que el contenido normativo sea ajustado por el propio legislador, para que el contenido siga correspondiendo con la realidad.

Cuando se supone que la norma tiene la posibilidad de operar para siempre, implica una visión estática de la realidad social y del derecho, generalmente nos lleva a una concepción iusnaturalista.

Si planteamos que la norma regula el deber ser, se considera que la distancia entre el deber ser y el ser, no es tan difícil de acortar. El ser puede diferenciarse de lo planteado por el deber ser previsto en la norma, pero como éste es lo ideal, la mejor solución posible a un conflicto determinado o futuro, el ser debe ajustarse a lo planteado por la norma (deber ser) y el primer paso hacia ello, es la creación de la norma que contiene el proyecto de relaciones interpersonales hacia el cual se quiere llevar a la sociedad.

Sin embargo, por lo general no están evidenciadas estas posibilidades. Converge aquí el elemento axiológico y el teleológico que era propio de posiciones iusnaturalistas y que es reconocido recientemente en algunas de las posiciones del llamado iuspositivismo incluyente. Bajo ese supuesto planteamos de nuevo dos posibilidades al sumar los elementos axiológico y teleológico:

La norma debe reflejar la realidad social, si y sólo si, la realidad social cumple con los valores que son propios de la misma sociedad.

De esta manera se considera justificado el hecho de la norma "simplemente" refleje lo que acontece en la realidad social.

La norma debe plantear un deber ser, al cual debe ajustarse la realidad social, sí y sólo si, el deber ser plantea la posibilidad de actualizar o concretar un conjunto de valores cuyo cumplimiento es necesario en el contexto de la sociedad. Lo más probable, en esta situación, es que la realidad social tenga un aspecto que es reconocido por la sociedad, a través de sus representantes (legisladores), como poco favorable y entonces se tenga la intención de modificarla paulatinamente (en algunas ocasiones de golpe, cuando se imponen sanciones para forzar el cumplimiento en determinado sentido).

Como se puede observar, los elementos axiológico y teleológico se asumen como condicionantes.

Sirve este preámbulo para tratar de situar los esfuerzos más recientes, hechos por el legislador mexicano, especialmente por el legislador del Distrito Federal, entidad donde residen los poderes federales y que tiene además, sus propios poderes 
locales, donde se implementaron una serie de reformas que tienen como propósito reforzar el cumplimiento de las obligaciones en materia de alimentos.

Es significativo el hecho que se lleve a cabo en el Distrito Federal, puesto que a pesar de que es la entidad federativa más pequeña, que ocupa menos de la milésima parte de la porción del territorio nacional, concentra casi el 8\% de la población nacional y ha sido, en muchas ocasiones, referente para las legislaciones del resto de las entidades y jurídicamente, dado que se ha considerado que en muchas ocasiones tiene disposiciones de "avanzada", entendiendo por ello el hecho de que amplía el reconocimiento y protección de derechos fundamentales de una manera que no se encuentra expresamente considerada en otros ordenamientos, justifica el adjetivo de "legislación de avanzada".

\section{EL SENTIDO COMÚN PRESENTE EN LAS NORMAS JURÍDICAS}

Se aclara que habitualmente se entiende por "sentido común:

"El sentido común son los conocimientos y las creencias compartidos por una comunidad y considerados como prudentes, lógicos o válidos. Se trata de la capacidad natural de juzgar los acontecimientos y eventos de forma razonable"1.

Bajo esta consideración, es posible suponer que es innecesario que el conjunto de conocimientos y creencias compartidos por una comunidad y que son considerados como prudentes, lógicos o válidos, deban reflejarse en una legislación, dado que se entiende que si son considerados de esa forma, son al mismo tiempo cumplidos por los integrantes de la propia comunidad o sociedad, y entonces su reflejo en la legislación es, reitero, innecesaria. Sin embargo, puede ser que el denominado "sentido común", sea menos común de lo que el propio concepto señala, de tal manera que refleje lo "común", ya sea perteneciente a un grupo social, a una etnia o a una clase social.

O se discute el sentido que tiene el concepto de "sentido común" o se amplía para incluir el hecho de una discreta relatividad: la posibilidad de que existan sociedades homogéneas en las cuales es posible encontrar "sentido común", por ejemplo una sociedad donde predomina (porcentualmente hablando y de manera superior al 90\%), un tipo de cultura (por ejemplo, pensemos en una cultura con tradición esencialmente occidental y cristiana, y es más se puede remarcar especialmente "protestante" o "católica") y donde el nivel de educación es homogéneo (pensemos que en promedio se tiene un nivel educativo de bachillerato concluido o un año de instrucción superior) y el nivel económico es también homogéneo (pensemos en un ingreso que ubica en promedio a la población en una clase media). Bajo ese contexto se puede comprender la idea del sentido común como un elemento real que hace innecesaria la presencia de la norma (al menos en ese conjunto de

\footnotetext{
${ }^{1}$ Definición de sentido común. Disponible en: <http://definicion.de/sentido-comun/\#ixzz2TZ8k0CYP>.
} 
conocimientos y creencias compartidas), de tal manera que puede entenderse por sentido común:

“(como el conjunto de) los conocimientos y creencias compartidos por una comunidad y considerados como prudentes, lógicos o válidos, sí y sólo sí, en esa comunidad se reúnen ciertas características de homogeneidad que permiten la existencia de dichos conocimiento y creencias compartidas, esto daría como consecuencia, que los individuos socializados bajo ese esquema tengan una capacidad, socialmente conformada ${ }^{2}$, de juzgar los acontecimientos y eventos de forma razonable".

Eso permitiría, reitero, obviar la presencia o la descripción de los conocimientos y creencias en las normas jurídicas y que los probables infractores de esas disposiciones previstas o derivadas del sentido común, puedan ver su comportamiento "reorientados" sobre la base de la reacción social informal (dado que no se previene una sanción en una norma jurídica).

El hecho es que existen sociedades de conformación muy heterogénea, en varios de los ámbitos, como el de edad, étnico, económico y cultural, que dificulta la conformación de los consensos necesarios para que los conocimientos y creencias sean verdaderamente "compartidos".

Eso implicaría que una idea de "sentido común" o es ilusoria (casi ingenua, dado que socialmente hablando no hay un conocimiento y creencia compartidas), o forma parte de un entramado cultural para justificar, sin evidenciar, la existencia de que predomina la visión, el conocimiento o criterios de un grupo social, clase o etnia.

En este caso, el mejor camino es el reconocimiento de esa diversidad y además, la intención de formar consensos entre los diversos grupos sociales que integran a la propia estructura social, de tal manera que es necesario que se exploren diversas soluciones a nivel legislativo y que se parta de que el contenido del mismo es simplemente la expresión de las fuerzas sociales que llegan a un acuerdo (esquema ideal) para determinar ciertas pautas de comportamiento y de relaciones interpersonales.

A partir de este punto, se retoma lo expuesto anteriormente, en el nivel teleológico se tiene, socialmente hablando, un propósito muy concreto, por ejemplo, negociar y establecer los mecanismos más eficaces para la relación interpersonal. En el nivel axiológico, se plantean los valores que deberán favorecer en la mejor medida, la convivencia pacífica y la solución de los conflictos más frecuentes y aún, tratar de imaginar la posibilidad de conflictos futuros y la mejor forma de solucionarlos.

${ }^{2}$ El término "natural" resulta tan problemático que se sustituye por un elemento más basado en evidencias sociológicas. 
En estas sociedades con gran diversidad estructural, pero con vocación democrática y de equidad, el "sentido común" es un concepto a definir y a construir, socialmente hablando.

\section{EL SENTIDO COMÚN PRESENTE EN LAS NORMAS JURÍDICAS QUE PLANTEAN}

\section{LA OBLIGACIÓN EN MATERIA DE ALIMENTOS}

Se parte de la idea de que en un contexto de homogenidad y conforme la cultura occidental y cristiana, se dan los siguientes supuestos culturalmente avalados:

La conformación de familias a partir de los esquemas formalmente reconocidos por la sociedad y sancionados por las normas (en un principio, solamente por las religiosas y posteriormente, además por las jurídicas).

La responsabilidad que tienen los padres de alimentar a los hijos, primeros en un sentido estricto de "responsabilizarse por dar alimentos" y posteriormente, se ha ido ampliando hasta considerar una serie de aspectos adicionales, aunque genéricamente se sigue hablando solamente de "alimentos".

El hecho de que esa obligación no cesa con la disolución del vínculo matrimonial, sino que prevalece hasta determinado momento, establecido como supuesto por la propia legislación.

El planteamiento de que habitualmente, la carga de la obligación alimentaria, tradicionalmente pesaba sobre el varón, y con las modificaciones en la realidad socialmente, al menos potencialmente hablando, irá aumentando con el paso de los años, el número de mujeres que se ubiquen en el supuesto de referencia (aunque proporcionalmente en este momento sea mayor el porcentaje de varones como deudores alimentarios, que de mujeres que sean deudoras alimentarias).

Si bien es cierto que la situación, en apariencia, más frecuente que se da, fuera del esquema del matrimonio, en el cual existe por supuesto la obligación de otorgar alimentos, es del divorcio, la idea derivada del sentido común (culturalmente discutible en nuestro contexto nacional) es que: la obligación de dar alimentos subsiste aunque se haya disuelto el vinculo matrimonial y muy especialmente subsiste si hay hijos derivados (o reconocidos) de ese vinculo.

Las excepciones son muy concretas y pueden derivar también del sentido común, entre ellas, las más significativas son:

- Que el acreedor llegue a la mayoría de edad;

- Que el deudor fallezca;

- Que el acreedor fallezca;

- Que el deudor se quede sin empleo.

Respecto del nivel de cumplimiento con las obligaciones alimentarias, no hay cifras fácilmente disponibles, no obstante, la Comisión Nacional de los Derechos Humanos señala que el incumplimiento es alto:

"3 de cada 4 hijos de padres separados, no reciben pensión alimenticia”. 
El $67.5 \%$ de las madres solteras no reciben pensión alimenticia como consecuencia de una serie de argucias que los deudores alimentarios implementan para evadir esa responsabilidad ${ }^{3}$.

Se está considerando en estos casos una sola forma de establecer la obligación alimentaria: la derivada del divorcio y el cargo se impone exclusivamente al varón, no se han considerado en los estudios estadísticos las obligaciones derivados de otras hipótesis consideradas por las propias normas, como por ejemplo lo relacionado con adoptante y adoptado; o entre ascendientes o parientes colaterales.

\section{Situación de la obligación de dar alimentos en la legislación CiVil del Distrito Federal, previa a las Reformas de 2011}

Las reformas que sufrió en casi tres cuartos de siglo de existencia del Código Civil para el Distrito Federal en materia de alimentos, parece que tuvo como finalidad simplemente afinar o puntualizar los detalles, por ejemplo, en el artículo 308, en el texto original de 1928 se indicaba:

"Lo alimentos comprenden la comida, el vestido, la habitación y la asistencia en casos de enfermedad. Respecto de los menores los alimentos comprenden, además, los gastos necesarios para la educación primaria del alimentista, y para proporcionarle algún oficio, arte $o$ profesión honestos y adecuados a su sexo y circunstancias personales"'

A partir de la reforma de $2000^{5}$, se adiciona el texto:

"I. La comida, el vestido, la habitación, la atención médica, la hospitalaria y en su caso, los gastos de embarazo y parto;

II. Respecto de los menores, además, los gastos para su educación y para proporcionarles oficio, arte o profesión adecuados a sus circunstancias personales;

III. Con relación a las personas con algún tipo de discapacidad o declarados en estado de interdicción, lo necesario para lograr, en lo posible, su habilitación o rehabilitación y su desarrollo; $y$

\footnotetext{
${ }^{3} \mathrm{CNDH}$ (2011). Primera Visitaduría, Coordinación del Programa sobre Asuntos de la Familia, la Niñez, Personas Adultas Mayores y Discapacidad. México. Disponible en: <http://ebookbrowse.com/11-bur\%C3\%93de-cr\%C3\%89dito-de-deudores-alimentarios-morosos-pptx-d420279284>. Los datos son obtenidos de organizaciones no gubernamentales, disponible en: <http://www.aldf.gob.mx/comsoc-persisten-morososalimentarios-df--12920.html>. Las mismas cifras de acuerdo con datos de organizaciones no gubernamentales, el $67 \%$ de los deudores alimentarios incumplen injustificadamente con su obligación, además, estadísticas oficiales indican que en México el $67.5 \%$ de las madres solteras no reciben pensión y en el Distrito Federal en promedio se presentan 2 mil demandas por pensión alimenticia por mes y sólo el $40 \%$ se resuelve.

${ }^{4}$ Texto original del Código Civil para el Distrito Federal. Disponible en: <http://biblio.juridicas.unam. $\mathrm{mx} / \mathrm{libros} / 1 / 260 / 7 . \mathrm{pdf}>$.

${ }^{5}$ De acuerdo con el Dr. Julián Güitrón Fuentevilla, la reforma se publica en la gaceta Oficial del DF el 25 de mayo de 2000, cf. Fuentevilla Güitrón, Julián y Roig Canal, Susana (2003). Nuevo Derecho Familiar en el Código Civil de México. Distrito Federal del año 2000. México: Porrúa, p. 183.
} 
$I V$. Por lo que hace a los adultos mayores que carezcan de capacidad económica, además de todo lo necesario para su atención geriátrica, se procurará que los alimentos se les proporcionen, integrándolos a la familia"6.

En un ámbito de "sentido común" no habría sido necesaria la incorporación de los supuestos adicionados en la reforma antes señalada, sin embargo, algo en la tendencia de la sociedad pareció hacer necesaria la aclaración, de tal manera que el texto familiar se vuelve más casuístico o al menos con supuestos más detallados.

\section{Reforma en el Código Civil para el DF en materia \\ DE RESPONSABILIDAD CIVIL}

Una de las novedades en materia de responsabilidad civil, la constituye la creación del registro de deudores alimentarios morosos. Esto se hace a través de un decreto promulgado el 26 de junio de 2011 por el entonces jefe de gobierno del Distrito Federal, Marcelo Ebrard, el cual fue publicado en la Gaceta Oficial del Distrito Federal el 18 de julio del mismo año, en el decreto se establece:

"Artículo primero.- Se reforman las fracciones VIII y IX del artículo 3043 y se adicionan los párrafos segundo, tercero y cuarto al artículo 35, un párrafo cuarto al artículo 97, los párrafos segundo, tercero y cuarto al artículo 309, un Capitulo IV "del Registro de Deudores Alimentarios Morosos" al Titulo Sexto con los articulos 323 Septimus y 323 Octavus y una fracción X al artículo 3043 del Código Civil para el Distrito Federal, para quedar como sigue:

Artículo 35....

El Registro Civil tendrá a su cargo el Registro de Deudores Alimentarios Morosos del Distrito Federal, en el que se inscribirá a las personas que hayan dejado de cumplir por más de noventa dias, sus obligaciones alimentarias, ordenadas por los jueces y tribunales o establecidas por convenio judicial. El registro expedirá un Certificado que informe si un deudor alimentario se encuentra inscrito en el Registro de Deudores Alimentarios Morosos.

El Registro Civil, una vez hecha la inscripción a que se refiere el párrafo anterior, formulará solicitud al Registro Público de la Propiedad a efecto de que se anote el Certificado respectivo en los folios reales de que sea propietario el Deudor Alimentario Moroso. El Registro Público de la Propiedad informará al Registro Civil si fue procedente la anotación.

El Registro Civil celebrará convenios con las sociedades de información crediticia a que se refiere la Ley de la materia, a fin de proporcionar la información del Registro de Deudores Alimentarios Morosos".

\footnotetext{
${ }^{6}$ Disponible en: <http://www.idconline.com.mx/media/2012/10/10/cdigo-civil-para-el-distrito-federal. $\mathrm{pdf}>$.

${ }^{7}$ Cf. Gaceta Oficial del Distrito Federal, 18 de julio de 2011.
} 
Respecto del artículo 97, la reforma establece:

I. a III. ...

$\cdots$

$\cdots$

El Juez del Registro Civil hará del conocimiento de los pretendientes inmediatamente después de la presentación de la solicitud, si alguno de ellos se encuentra inscrito en el Registro de Deudores Alimentarios Morosos.

Lo relevante de la disposición anterior, es el refuerzo que se hace para orientar el cumplimiento del deudor alimentario en el sentido de cumplir con sus obligaciones y que involucra dos posibilidades al menos: que el deudor se quiera casar de nuevo o que no lo desee hacer, situaciones que tiene sendas consecuencias que serán analizadas posteriormente.

Suponiendo, sin conceder, que el deudor alimentario lo es porque se ha separado de su pareja previa y está incumpliendo, de manera dolosa, con sus obligaciones alimentarias, no está impedido por ese hecho para poder contraer nuevo matrimonio, pero la autoridad, a partir del registro antes mencionado, puede "dar a conocer" a la nueva pareja el hecho que el obligado está en la situación de "deudor moroso". Las repercusiones del hecho no rebasan ese ámbito.

Sigue en el decreto de reforma:

Artículo 309...

Aquella persona que incumpla con lo señalado con el párrafo anterior por un periodo de noventa días se constituirá en deudor alimentario moroso. El Juez de lo Familiar ordenará al Registro Civil su inscripción en el Registro de Deudores Alimentarios Morosos.

El deudor alimentario moroso que acredite ante el Juez que han sido pagados en su totalidad los adeudos a que se refiere el párrafo anterior, podrá solicitar al mismo la cancelación de la inscripción.

El Registro Civil cancelará las inscripciones a que se refiere el segundo párrafo previa orden judicial.

Capitulo IV

Del Registro de Deudores Alimentarios Morosos

Artículo 323 Septimus. En el Registro de Deudores Alimentarios Morosos se harán las inscripciones a que se refiere el artículo 309 del presente Código. Dicho registro contendrá:

I. Nombre, apellidos y Clave Única del Registro de Población del deudor alimentario moroso;

II. Nombre del acreedor o acreedores alimentarios;

III. Datos del acta que acrediten el vinculo entre deudor y acreedor alimentario, en su caso; 
IV. Número de pagos incumplidos y monto del adeudo alimentario;

V. Órgano jurisdiccional que ordena el registro; $y$

VI. Datos del expediente o causa jurisdiccional de la que deriva su inscripción.

Artículo 323 Octavus. El certificado a que se refiere el artículo 35 de este Código contendrá lo siguiente:

I. Nombre, apellidos y Clave Única de Registro de Población del deudor alimentario moroso;

II. Número de acreedores alimentarios;

III. Monto de la obligación adeudada;

IV. Órgano jurisdiccional que ordenó el registro, y

V. Datos del expediente o causa jurisdiccional de la que deriva su inscripción.

El Certificado a que se refiere el presente artículo, será expedido dentro de tres días hábiles contados a partir de su solicitud.

Artículo 3043.- Se anotarán previamente en el Registro Público:

I a VII. ...

VIII. Las resoluciones judiciales en materia de amparo que ordenen la suspensión provisional o definitiva, en relación con bienes inscritos en el Registro Público;

IX. Cualquier otro título que sea anotable, de acuerdo con este Código u otras Leyes, y

$X$. El Certificado del Registro de Deudores Alimentarios Morosos a que se refiere el artículo 35 del presente Código.

En el artículo segundo del decreto que es motivo de análisis se establecen una serie de reformas en el ámbito del derecho penal, a saber:

Artículo segundo.- Se reforma el primer párrafo y se adiciona un párrafo cuarto al artículo 193 del Código Penal para el Distrito Federal, para quedar como sigue:

Articulo 193. Al que incumpla con su obligación de dar alimentos a las personas que tienen derecho a recibirlos, se le impondrá de tres a cinco años de prisión y de cien a cuatrocientos días multa, suspensión o pérdida de los derechos de familia, y pago como reparación del daño a las cantidades no suministradas oportunamente. Si el adeudo excede de noventa días, el Juez ordenará al Registro Civil el ingreso de los datos del sentenciado en el Registro de Deudores Alimentarios Morosos.

Una vez que el sentenciado cumpla con la reparación del daño, el Juez a petición de parte deberá ordenar al Registro Civil la cancelación de la inscripción. 
Esta reforma debe analizarse en el contexto del capítulo único del Título Séptimo: "De los delitos que atentan contra el cumplimiento de la obligación alimentaria" y que es motivo de una revisión ulterior.

La doctrina se apresuró a analizar y recoger la nueva institución creada, ejemplo de ello lo plantea Javier Tapia quien define al Registro como: "el sistema administrativo creado para constreñir a las personas que legalmente están obligadas a proporcionar alimentos, a no dejar de cumplir con sus obligaciones alimentarias, so pena de hacer pública tal conducta en un registro creado ad hoc y que está a cargo del registro civil; así como de inscribir en el registro público de la propiedad tal incumplimiento efectuando las habitaciones correspondientes en los bienes de los deudores alimentarios morosos" 8 .

Desde el punto de vista del jurista, especialmente del que comparte una perspectiva de carácter formalista, la existencia misma de la norma es un punto de partida fundamental para poder orientar la conducta de los seres humanos que viven en sociedad. Si no existe la norma, es poco probable que la sociedad pueda orientar el comportamiento de sus integrantes, a menos que la conducta o una orientación que se desee establecer tenga sus raíces en la costumbre o en las convicciones morales más profundas del grupo social.

La reforma afectó también a la parte del derecho penal con el cual tiene vínculo el tema de la obligación de otorgar alimentos.

Delitos que atentan contra el cumplimiento de la obligación alimentaria

Capitulo único

Artículo 193. Al que incumpla con su obligación de dar alimentos a las personas que tienen derecho a recibirlos, se le impondrá de tres a cinco años de prisión y de cien a cuatrocientos dias multa, suspensión o pérdida de los derechos de familia, y pago como reparación del daño a las cantidades no suministradas oportunamente. Si el adeudo excede de noventa días, el Juez ordenará al Registro Civil el ingreso de los datos del sentenciado en el Registro de Deudores Alimentarios Morosos.

(Reformado, G.O., 22 de julio de 2005).

Para los efectos de este Artículo, se tendrá por consumado el delito aun cuando el o los acreedores alimentarios se dejen al cuidado o reciban ayuda de un tercero.

(Reformado, G.O., 22 de julio de 2005).

Cuando no sean comprobables el salario o los ingresos del deudor alimentario, para efectos de cubrir los alimentos o la reparación del daño, se determinarán con base en la capacidad económica y nivel de vida que el deudor y sus acreedores alimentarios hayan llevado en los dos últimos años.

N. de E. en relación con la entrada en vigor del presente párrafo, véase transitorio primero del decreto que modifica el Código.

(Adicionado, G.O., 18 de agosto de 2011).

${ }^{8}$ Tapia Ramírez, Javier (2013). Derecho de Familia. México: Porrúa, p 273. 
Una vez que el sentenciado cumpla con la reparación del daño, el Juez a petición de parte deberá ordenar al Registro Civil la cancelación de la inscripción.

(Reformado, G.O. 22 de julio de 2005).

Artículo 194. Al que renuncie a su empleo o solicite licencia sin goce de sueldo y sea éste el unico medio de obtener ingresos o se coloque en estado de insolvencia, con el objeto de eludir el cumplimiento de las obligaciones alimentarias que la ley determina, se le impondrá pena de prisión de uno a cuatro años y de doscientos a quinientos días multa, pérdida de los derechos de familia y pago, como reparación del daño, de las cantidades no suministradas oportunamente.

(Reformado, G.O. 22 de julio de 2005).

Articulo 195. Se impondrá pena de seis meses a cuatro años de prisión y de doscientos a quinientos días multa a aquellas personas que obligadas a informar acerca de los ingresos de quienes deban cumplir con todas las obligaciones señaladas en los Articulos anteriores, incumplan con la orden judicial de hacerlo o haciéndolo no lo hagan dentro del término ordenado por el Juez u omitan realizar de inmediato el descuento ordenado.

(Reformado, G.O. 22 de julio de 2005).

Artículo 196. Para el caso de que la persona legitimada para ello otorgue el perdón, sólo procederá si el indiciado, procesado o sentenciado paga todas las cantidades que hubiere dejado de proporcionar por concepto de alimentos y otorgue garantía cuando menos por el monto equivalente a un año.

(Reformado, G.O. 22 de julio de 2005).

Artículo 197. Si la omisión en el cumplimiento de las obligaciones alimentarias, ocurre en incumplimiento de una resolución judicial, las sanciones se incrementarán en una mitad.

Artículo 198. (Derogado, G.O. 22 de julio de 2005).

(Reformado, G.O. 22 de julio de 2005).

Articulo 199. Los delitos previstos en este Título se perseguirán por querella.

\section{Primeras impresiones del fenÓmeno una Vez Que SE IMPLEMENTARon}

\section{LAS REFORMAS CORRESPONDIENTES}

Entre los legisladores de nuestro país se generó un clima de optimismo al ser implementado el registro antes mencionado, de tal forma que la Presidenta de la comisión de gobierno de la asamblea legislativa, Alejandra Barrales calificó como un avance importante en favor de los niños las reformas a los Códigos Civil y Penal del Distrito Federal por el que se quería el registro de deudores alimentarios morosos:

"Estamos muy contentos. A partir del 18 de setiembre quienes no cumplan con su obligación de pagar pensiones alimenticias, tendrán que pagarlo con cárcel, sentencia que podría llegar hasta los cinco años atrás... Detalló que estas reformas, que presentó a nombre propio y del diputado Julio César Moreno ante el pleno de la Asamblea 
Legislativa del Distrito Federal y que se publicaron ayer en la Gaceta Oficial del Distrito Federal, constituyen un respaldo para el bienestar de los niños y niñas de la ciudad de México, ya que se les garantiza su derecho a la alimentación, educación y recreación"'.

Ciertamente, uno de los derechos más significativos que se pretende proteger con esta medida radica en garantizar el derecho a la alimentación, en primer lugar, y de manera secundaria la educación y la recreación. Sin embargo, lo más importante puede ser considerado el primero de los derechos, dado que es el punto de partida para que se puedan gozar los siguientes.

Por su parte, el Presidente de la comisión de administración y procuración de justicia, Julio César Moreno, señaló que:

"La pena actual era de seis meses a cuatro años de prisión, o de 90 a 360 días de multa; estamos hablando de un delito menor de pena no privativa de la libertad y en caso de que fuera consignado, el deudor recibiría una orden de presentación y no de aprehensión. Eso era una burla, no había modo de que se les pudiera obligar a cumplir con la tensión; ahora la pena privativa de libertad no establece como delito grave, pero también le dan oportunidad al deudor de cumplir con su orden" 10 .

El aumento de la penalidad, por supuesto, se convierte en un factor disuasivo o al menos se pretende que así sea, aunque para ello sería necesario revisar otros aspectos adicionales a lo jurídico. Los legisladores consideran que todavía hay aspectos por tratar en la materia, por ejemplo:

Reconoció (Alejandra Barrales) que habrá casos especiales como aquellos que por falta de empleo la persona carece de recursos económicos. Esta situación se revisa porque a nadie se le puede obligar a lo imposible, en los casos cuando no se pueda, lo cual es muy diferente a no querer pagar la pensión ${ }^{11}$.

Bajo una perspectiva de género, mencionó la propia legisladora:

El siguiente paso será apoyar a los padres cumplidos con las pensiones de sus hijos, ya que se ha identificado el problema que la mayoría de las madres de familia son las que impiden primordialmente a sus ex maridos convivir con los menores de edad. Eso lo tenemos que resolver para ser muy equitativos. ${ }^{12}$

Se plantea la idea de que el deudor alimentario tiene por supuesto la obligación de otorgar alimentos, pero, en el caso de las obligaciones que se establecen

\footnotetext{
${ }^{9}$ Disponible en: <http://www.aldf.gob.mx/comsoc-registro-deudores-alimentarios-morosos-protegera-losninos-y-ninas-df--8510.html>.

${ }^{10}$ Disponible en: <http://www.aldf.gob.mx/comsoc-avanza-registro-deudores-alimentarios-morosos--7739. html>.

${ }^{11}$ Disponible en: <http://www.aldf.gob.mx/comsoc-registro-deudores-alimentarios-morosos-protegera-losninos-y-ninas-df--8510.html>.

12 Ídem.
} 
de padres a hijos (y cónyuge), el deudor tiene además un derecho: el de convivir con los menores de edad.

En la dinámica contemporánea de las relaciones que se dan entre los ex cónyuges, hay ocasiones en las cuales los hijos son usados como un instrumento de violencia moral, sin que se llegue a dimensionar el daño que se puede causar a los hijos por ese hecho, lo relevante en el momento, consiste en causar una aflicción moral al ex cónyuge que es visto como "el enemigo". Ese hecho parece que no ha sido suficientemente analizado, aunque se ha acuñado el concepto de Síndrome de Alienación Parental (SAP) para analizar el efecto del divorcio, especialmente del conflictivo y sus respectivas secuelas, sobre los hijos. El propio divorcio dispara efectos negativos como:

- Baja en el rendimiento académico.

- Peor autoconcepto.

- Dificultades en las relaciones sociales.

- Dificultades emocionales como depresión, miedo, o ansiedad entre otras.

- Problemas de conducta ${ }^{13}$.

Estos trastornos pueden ser considerados como temporales, en tanto se da el proceso de separación legal, sin embargo, muchos de ellos persisten tiempo después de que se concluyó con la separación jurídica y se lleva a cabo la material, esto es, uno de los cónyuges abandona el hogar y el otro se queda con la custodia de los hijos. Concluye el matrimonio de manera formal, pero subsiste el conflicto interpersonal que motivó la separación y los hijos son usados como armas ${ }^{14}$.

13 "Problemas psicológicos en los hijos por el divorcio de los padres". Disponible en: <http://www.fundacionbelen.org/taller/divorcio.html>.

${ }^{14}$ En relación con el denominado Síndrome de Alienación Parental, se enumeran al menos los siguientes efectos en los hijos comunes:

- Campaña de rechazo y difamación: los niños al relatar se tensionan mucho y casi nunca, interrogados, son capaces de concretar algo.

- Racionalizaciones absurdas: las justificaciones aportadas por los niños para defender sus posiciones hostiles e irracionales no tienen conexión real con la experiencia verdadera.

- La falta de ambivalencia normal: un padre es todo bueno y el otro es todo malo.

- La inclinación automática hacia el padre programador: los parientes toman parte incondicional hacia el padre con custodia.

- La ampliación, por parte del niño, de las hostilidades a toda la familia y el entorno del padre no custodio: con fundamentos absurdos y distorsionados.

- El fenómeno de la "opinión propia": los niños desde muy chicos tienen una opinión formada acerca de hechos muy complejos y dolorosos.

- Ausencia de sentimiento de culpa por la crueldad hacia el padre no custodio: acompañada por exigencia económica sin escrúpulo.

- La adopción de escenarios prestados: por el padre custodio para acusar al otro, frente a los cuales el niño cuando es interrogado muestra total incoherencia e incomprensión.

- PAS Leve: todavía el trato con el padre no custodio existe, se recomienda dejar la custodia al padre programador pero con condicionamientos judiciales estrictos acerca del derecho de trato y visita.

- PAS Moderado: cuando hay presencia de síntomas relevantes en el niño y problemas de trato y visita con el padre no custodio, se recomienda dejar la custodia al padre programador pero con el cuidado de un 
Entonces, la idea planteada por la legisladora Alejandra Barrales como uno de los pendientes de la institución, parece necesaria en el contexto de la equidad y de la perspectiva de género.

De lo referido por ambos legisladores, se puede concluir que la institución del Registro de Deudores Alimentarios Morosos se encuentra en proceso de construcción, se están dando los pasos para implementarlo para que sea una institución eficaz que promueva el cumplimiento de las obligaciones alimentarias, por lo pronto en la ciudad de México y se espera que dicha institución constituya un modelo a seguir en el resto de las entidades federativas.

\section{Resultados del Registro hasta mayo de 2013}

Como toda institución naciente, el Registro de Deudores Alimentarios Morosos, no ha cumplido, a poco menos de un año, con las expectativas que se determinaron en el mismo, de acuerdo con lo que señaló en marzo de 2013 un diputado:

"El diputado perredista, Eduardo Santillán Pérez, afirmó que sólo se encuentran inscritos en el Registro de Deudores Alimentarios Morosos (REDAM) 24 morosos alimentarios hasta el 31 marzo del presente año, desde la aprobación de la reforma al Código Civil, el pasado 18 de agosto de 2011"15.

Propuestas hechas adicionalmente a las contenidas en la reforma de 2012.

Para afianzar el cumplimiento de la norma el diputado Eduardo Santillán propone:

"Establecer el embargo precautorio hacia aquellos padres que traten de evadir el pago de pensiones alimenticias y violenten los derechos de niñas, niños y adolescentes y un punto de acuerdo para exhortar a la Consejería Jurídica y Servicios Legales y al Tribunal Superior de Justicia ambos del Distrito Federal a que celebren convenios de colaboración con las Sociedades de Información Crediticia y a efecto de poder registrar a los deudores alimentarios ante las mismas, a lo cual dichas Sociedades han respondido de manera favorable".

"De tal suerte que con esta acción se pretende que todos los deudores alimentarios sean boletinados en el denominado "Buró de crédito" y "Círculo de Crédito" y con ello evitar que dichas personas puedan acceder a créditos, ya que "si una persona no paga alimentos a sus hijos; no puede ser sujeto de crédito".

asistente social que acompañe y programe las visitas del/al padre no custodio e informe el tribunal cuando el trato no funcione.

- PAS Grave: cuando existe una completa y obstinaba negación por parte del padre programador a la visita y al trato con el padre no custodio que se ven así completamente interrumpidas, se recomienda la transferencia del derecho de custodia a este último.

Cf. Ídem.

${ }^{15}$ Asamblea Legislativa del Distrito Federal (2013). "Persisten morosos alimentarios en el DF”. Disponible en: <http://www.aldf.gob.mx/comsoc-persisten-morosos-alimentarios-df--12920.html>. 
"Comentó que uno de los asuntos más graves no es que sólo existan 24 registros de morosos, sino que con el hecho de serlo no tengo mayor implicación"16.

Adicionalmente, la periodista Julieta Lujambio propone:

Condicionar la expedición de pasaportes, licencias, credencial de elector y otros documentos oficiales al no adeudo de dicha pensión.

Promover ante la Comisión de Justicia de las Cámaras de Senadores y Diputados, las siguientes propuestas:

- Reformar el Código Penal Federal o motivar la presentación de iniciativas de reforma a los Códigos Locales para imponer penas a cualquier persona física o moral que incurra en declaraciones de falsedad u ocultamiento de verdad en los procedimientos por alimentos.

- Equiparar al delito de fraude la renuncia del deudor alimentista a su trabajo para eludir la obligación de pagar pensión alimenticia.

- Promover la simplificación de los procedimientos civiles en materia de alimentos, con el objetivo de que tanto las mujeres como los menores y personas con discapacidad o dependientes tengan acceso a la justicia pronta y expedita. Nota: Es necesario que el Estado en lugar de asumir las responsabilidades de los padres con sus hijos, promueva la procuración de justicia y el cumplimiento de sus normas, por lo cual se considera que las iniciativas y programas públicos de promover la penalización a las personas que evaden sus obligaciones. En la medida en que los hombres acepten su corresponsabilidad en la crianza y educación de sus hijos, el Estado reducirá el gasto social en la materia y se promoverá una verdadera cultura de equidad de género y responsabilidades familiares compartidas ${ }^{17}$.

Dada la naturaleza de la propuesta se entiende el uso del lenguaje, dado que la propuesta debería señalar simplemente: "Promover la simplificación de los procedimientos civiles en materia de alimentos, con el objetivo de que tanto los deudores alimentarios, los menores y personas con discapacidad o dependientes tengan acceso a la justicia pronta y expedita”. Dado que de acuerdo con las reformas recientes en materia de matrimonio (reconocimiento de matrimonios de personas del mismo sexo) y del uso no discriminatorio del lenguaje, se puede considerar casos que anteriormente no eran muy visibles para la sociedad en razón de que las situaciones eran ocultadas (el caso de los divorcios de matrimonio del mismo sexo y de abandono de personas que estuvieron en relaciones con otras del mismo sexo).

\footnotetext{
16 Ídem.

${ }^{17}$ Disponible en: <http://www.mamasola.com/PropuestaCiudadanaContenido.php?id=6>.
} 


\section{LOS ELEMENTOS DE CARÁCTER ECONÓMICO}

Uno de los factores de incumplimiento de las obligaciones alimentarias, que deriva en una morosidad, puede ser el factor económico. Dado que en los últimos años la economía, en su nivel de familias o individual, ha estado a la baja, el desempleo abierto ha aumentado, los salarios se han estancado y en términos generales hay una pérdida significativa del poder adquisitivo de las personas.

Para principios de 2012 se agudizó el desempleo:

A menos de seis meses de que concluya el gobierno de Felipe Calderón, el desempleo en México continuará durante este año en niveles superiores al 5\%, reveló la Organización para la Cooperación y del Desarrollo Económico (OCDE).

En otras palabras, el número de personas sin trabajo en México rondará en unos 2,5 millones, ya que el desempleo se reducirá hasta los primeros meses del 2013; mientras que la informalidad se encuentra en condiciones "preocupantes", según la organización encabezada por José Ángel Gurría.

Al dar a conocer el reporte Panorama de Empleo 2012, el organismo internacional señaló que "México ha experimentado una recuperación económica más robusta que la mayoría de los países de la OCDE, en conjunción con un fuerte crecimiento del empleo, sin embargo, la tasa de desempleo aún no desciende hasta su nivel pre-crisis". Antes del 2009 la tasa de desocupación era menor al 5\%18.

En esa misma fecha, un estudio llevado a cabo por un organismo de la UNAM, revela una realidad más fuerte en materia de desempleo: "El número real de desempleados en México es de 8,7 millones de personas y no los 2,4 millones que el Inegi identificaba como población desocupada al cierre de 2011, sostiene un estudio del Centro de Análisis Multidisciplinario (CAM) de la UNAM. En su más reciente reporte de investigación, el órgano señala que el gobierno mexicano ha encubierto las cifras reales de desempleo en el país, debido a que la metodología que utiliza el Inegi para medir la tasa de desocupación no es pertinente, dado que dicha tasa sólo contempla 'a los desocupados que activamente han buscado trabajo durante el último mes', pero deja de lado a quienes ya se cansaron de buscar o ya no creen tener oportunidad de encontrarlo" 19.

Asimismo agrega que:

"Con la tasa de desocupación, el gobierno no sólo está ocultando al 72\% de la población desempleada, sino que no se está contemplando a quienes sufren de una situación crónica de desempleo", señala el análisis elaborado por los investigadores Jaime Vázquez, Luis Lozano Arredondo y David Lozano Tovar, entre otros"20.

18 "En 2012 el desempleo en México seguirá en niveles superiores a 5\%: OCDE”. Disponible en: <http:// www.proceso.com.mx/?p=313813>.

19 "Oculta el gobierno las cifras reales del desempleo: estudio". Disponible en: <http://www.jornada.unam. $\mathrm{mx} / 2012 / 04 / 12 /$ economia/024n1eco>.

${ }^{20}$ Ídem. 
Las cifras entonces, de desempleo, parecen ser más graves que los datos proporcionados por el gobierno. Respecto de los afectados por el desempleo, tampoco hay cifras muy consistentes, en ocasiones parece ser que el desempleo afecta más a los hombres y en otras a las mujeres:

La tasa de desempleo en el país se ubicó en octubre pasado en 5,04\% de la Población Económicamente Activa (PEA), una tasa similar al 5,0\% registrado en igual mes de 2011, informó el Instituto Nacional de Estadística y Geografía (INEGI). La tasa de desempleo en el país se ubicó en octubre pasado en 5,04\% de la Población Económicamente Activa (PEA), una tasa similar al 5,0\% registrado en igual mes de 2011, informó el Instituto Nacional de Estadística y Geografía (INEGI)... En su reporte, el organismo indica que a tasa anual, la tasa de desocupación en los hombres se redujo de $5,08 \%$ a 4,98\% y la de las mujeres creció de $4,88 \%$ a $5,14 \%$ en el mismo lapso ${ }^{21}$.

En la norma se reconoce el supuesto de la falta de empleo, situación contemplada en la hipótesis de la fracción I del artículo:

Artículo 320.- Se suspende o cesa, según el caso, la obligación de dar alimentos, por cualquiera de las siguientes causas:

I. Cuando el que la tiene carece de medios para cumplirla;

II. Cuando el alimentista deja de necesitar los alimentos;

III. En caso de violencia familiar o injurias graves inferidas, por el alimentista mayor de edad, contra el que debe prestarlos;

IV. Cuando la necesidad de los alimentos dependa de la conducta viciosa o de la falta de aplicación al estudio del alimentista mayor de edad;

V. Si el alimentista, sin consentimiento del que debe dar los alimentos, abandona la casa de éste por causas injustificables; $y$

VI. Las demás que señale este Código u otras leyes ${ }^{22}$.

Del total de deudores alimentarios morosos se supone que se excluye el porcentaje de incumplidos que lo hacen bajo el supuesto de la fracción I del artículo 320; sin embargo, habría que corroborar efectivamente ese dato.

Ignoro que tendrá mayor peso, si el aspecto de carácter económico o el aspecto cultural en el incumplimiento de la obligación de otorgar alimentos, de tal mane-

21 "El INEGI reportó que, en general, la tasa de desempleo se mantuvo estable, aunque aumentó el número de mujeres desocupadas". Disponible en: <http://noticierostelevisa.esmas.com/economia/528904/disminuyedesempleo-masculino-aumenta-femenino/>.

22 Disponible en: <http://www.idconline.com.mx/media/2012/10/10/cdigo-civil-para-el-distrito-federal. pdf $>$. 
ra que en una adecuada política pública, ambos aspectos deberían ser cubiertos, además de que se refuercen los elementos de carácter cultural y educativo.

\section{LOS ELEMENTOS CULTURALES DEL INCUMPLIMIENTO}

Se puede hablar de una cultura o subcultura, no entraré en detalles, respecto de la denominación, que no favorece el cumplimiento de las obligaciones del deudor alimentario. Frente a la obligación de dar alimentos especialmente cuando ha cesado el vínculo matrimonial, hay incluso una expresión, ignoro si muy mexicana o si es también propia de otras latitudes tercermundistas o latinoamericanas de “iPor qué he de mantenerla (los) si ni siquiera es de mi familia!"

Tradicionalmente la educación machista ${ }^{23}$ en nuestro país, ha sido un impedimento muy fuerte para lograr la igualdad y la equidad entre sexos a un nivel que trascienda los aspectos estrictamente formales.

Formalmente, desde hace varias décadas, existe la igualdad entre el hombre y la mujer y la legislación, concretamente la del Distrito Federal y muchas de las resoluciones de la Suprema Corte de Justicia apuntan hacia esa dirección, especialmente al autorizarse la celebración de matrimonios entre personas del mismo sexo. El problema es que en este sentido, muchos de los discursos dominantes en la sociedad siguen siendo profundamente machistas y muchos de ellos misóginos ${ }^{24}$ los cuales derivan en muchas ocasiones, en una actitud de prepotencia (propia del machismo "simple", hasta en la violencia física o emocional en contra de un grupo muy enfocado de mujeres o en contra de todas las mujeres o de las mujeres en general, el cual pueden desembocar incluso en la agresión concreta, en el homicidio o en el feminicidio).

Los medios de comunicación en nuestro país, especialmente los caracterizados a través del oligopolio (descrito como duopolio) de los medios televisivos (que concentran una parte muy importante del espectro de la audiencia en nuestro país ${ }^{25}$ )

\footnotetext{
${ }^{23}$ En el Diccionario de la Real Academia se define al machismo como: "1.m. Actitud de prepotencia de los varones respecto de las mujeres". Disponible en: <http://lema.rae.es/drae/?val=machismo $>$. Sin embargo, la idea expuesta en ese lexicón se queda corta con los alcances del fenómeno; dado que se puede hablar de un concepto genérico de machismo en el cual se engloba a la misoginia.
}

El desarrollo del discurso antifemenino (que habría que distinguirlo en algún momento del discurso "antifeminista") va a la par del desarrollo de la sociedad, de tal forma que Mariano Nieto y Sáenz hablan de un machismo postmoderno: "Muy preocupante, en particular, es el discurso posmachista que, bajo una adhesión formal a la igualdad y tomándola como pretexto, descalifica como "revanchista” la reivindicación y la acción igualitaria del feminismo e insinúa que esa acción es responsable, en parte, de la violencia machista ejercida contra las mujeres". Disponible en: <http://www.stopmachismo.net/25n.htm>.

${ }^{24}$ En el propio diccionario de la RAE se define a la misoginia como: "1. f. Aversión u odio a las mujeres". Disponible en: $<$ http://lema.rae.es/drae/?val=misoginia $>$.

${ }^{25}$ Las cifras son relativamente inciertas, los propios medios difunden cifras muy altas de audiencia, en tanto estudios realizados por otras organizaciones plantean un escenario en el futuro menos promisorio para la llamada televisión abierta, esto es: "estima que el rating promedio anual de TV abierta disminuirá en 3\% 
y radiofónicos que abarcan prácticamente la mayor parte del espectro informativo y de cultura informal de nuestro país, no son precisamente muy asertivos con las políticas de género, de igualdad y sobre todo de cumplimiento con las obligaciones, pasando por encima de los esquemas de machismo.

Ya constituye un lugar común el hablar de la educación como una de las soluciones primordiales a los problemas ingentes de nuestro país, sin embargo, en este caso, a pesar de nuestra procedencia como estudiosos del derecho y en muchos momentos como operadores del mismo y de nuestra inercia de tratar de resolver la mayor parte de los problemas a través de nuevas normas que incluyan sanciones más severas, en este caso es de resaltar la importancia de una cultura de la "prevención" y esta se dará muy especialmente a través de la educación, de la educación formal y de la incidencia de la universidad sobre la sociedad a través de los medios que tenga disponibles.

\section{Consideraciones finales}

En nuestro ámbito nacional y muy especialmente en el local, se han dado avances muy importantes en muchas materias, que tal vez, teóricamente nos colocarían a la vanguardia de la normatividad en nuestro país, entre ellas por supuesto, la creación de las sociedades de convivencia y posteriormente, el matrimonio entre personas del mismo sexo y muy recientemente, en un ánimo por tratar de desterrar o aminorar los efectos de la falta de cumplimiento de las obligaciones de los acreedores alimentarios a través de la creación del Registro de Deudores Alimentarios Morosos.

Sin embargo, esas nuevas disposiciones no han permeado, dos años después, en la normatividad de otras entidades federativas, ni tampoco, al parecer, de acuerdo con lo expresado por algunos de los especialistas referenciados, en la sociedad misma, dado que hasta el momento de cierre de esta reflexión no estaba totalmente consolidado el referido registro.

El fenómeno de incumplimiento tiene al menos dos aspectos muy relevantes, uno económico y otro, cultural. Ignoro cuál de ellos tiene mayor peso, si el aspecto

de 2008 a 2011, contrariamente a la TV restringida que se incrementará en 42\%. Asimismo, la participación de audiencia o 'share' promedio anual de TV abierta se espera que disminuya en 7\%, mientras que la TV de paga crecerá en 36\% entre 2008 y 2011. En ese sentido, afirma que el impacto de la TV de paga se verá con mayor fuerza en los segmentos de la población de mayor poder adquisitivo o mayor afinidad a una programación más dirigida. Así, el objetivo de individuos de 13 a 18 años en los niveles $\mathrm{ABC}+\mathrm{C}$ el rating se incrementa en un 54\% y el share en 36\%". Disponible en: <http://www.cnnexpansion.com/ negocios/2011/10/18/canales-de-tv-cuestionan-rating-mexicano $>$. Las cifras aquí señaladas corresponden a un estudio hecho por LAMAC (Consejo Latinoamericano de Multicanales) y es del año de 2010 con proyecciones al 2011. Aun así, el escándalo mediático generado por el denominado "apagón analógico" en la ciudad de Tijuana a finales del mes de mayo de 2013, es una muestra del poder de convocatoria que tienen los dos grupos monopólicos de televisoras. Cf. Al respecto: "Pide la SCT a la Cofetel aplazar el apagón hasta después de comicios”, disponible en: <http://www.jornada.unam.mx/2013/05/31/economia/021n1eco>. 
de carácter económico o el aspecto cultural en el incumplimiento de la obligación de otorgar alimentos, de tal manera que en una adecuada política pública, ambos aspectos deberían ser cubiertos, además de que se refuercen los elementos de carácter cultural y educativo. 